\title{
Production of essential oils from in vitro cultures of Caryopteris species and comparison of their concentrations with in vivo plants
}

\author{
Maria Luczkiewicz • Anna Jesionek • Adam Kokotkiewicz • \\ Piotr Migas · Marek Mardarowicz • Aleksandra Szreniawa-Sztajnert • \\ Bozena Zabiegala $\cdot$ Adam Bucinski
}

Received: 10 July 2014/Revised: 29 December 2014/Accepted: 7 February 2015/Published online: 21 February 2015

(C) The Author(s) 2015. This article is published with open access at Springerlink.com

\begin{abstract}
The chemical composition of hydrodistilled essential oils obtained from aerial parts and roots of selected Caryopteris ('bluebeard') species (C. incana, $C$. mongolica, Caryopteris $\times$ clandonensis), as well as the newly established in vitro shoot and adventitious root cultures of the above plants, was analyzed by gas chromatography-mass spectrometry. Essential oil content and composition differed significantly depending on the type of plant material analyzed. Adventitious roots were characterized by the highest essential oil yield, reaching $1.8 \%$ V/DW in Caryopteris $\times$ clandonensis. Limonene and cedrol were the main components of the essential oil derived from aerial parts of the intact plants (11.9-16.0 and $10.7-10.9 \%$, respectively), whereas the volatile fractions
\end{abstract}

Communicated by K.Y. Paek.

M. Luczkiewicz ( \) A A Jesionek · A. Kokotkiewicz · P. Migas

Department of Pharmacognosy, Faculty of Pharmacy, Medical University of Gdansk, Al. Gen. J. Hallera 107,

80-416 Gdansk, Poland

e-mail: mlucz@gumed.edu.pl

M. Mardarowicz

Analytical Laboratory, Faculty of Chemistry, Maria Curie-

Sklodowska University, Plac M.C. Skłodowskiej 3/9,

20-031 Lublin, Poland

A. Szreniawa-Sztajnert · B. Zabiegala

Department of Analytical Chemistry, Chemical Faculty, Gdansk University of Technology, ul. Gabriela Narutowicza 11/12, 80-233 Gdansk, Poland

\footnotetext{
A. Bucinski

Department of Biopharmacy, Faculty of Pharmacy, Ludwik

Rydygier Collegium Medicum in Bydgoszcz, Nicolaus

Copernicus University in Torun, ul. dr A. Jurasza 2,

85-089 Bydgoszcz, Poland
}

of the in vivo roots of all species contained large amounts of 3,5-bis(1,1-dimethyl)-phenol (12.9-26.2\%). 1,8cineole, absent in the intact plant materials, was the dominating volatile constituent of the essential oils obtained from in vitro shoots (24.8-34.2\%). The volatile oil derived from adventitious root cultures consisted primarily of 1-octen-3-ol (19.7-31.5\%) and medicinally relevant diterpenoids: abietatriene and trans-totarol, which were accumulated in considerable quantities, especially in the adventitious roots of C. clandonensis (21.6 and $29.2 \%$, respectively).

Keywords Abietatriene - Adventitious roots . Caryopteris · In vitro shoots · Totarol

\section{Introduction}

The genus Caryopteris [formerly placed in Verbenaceae, currently assigned to Labiatae (Cantino et al. 1999)] includes hardy, small, deciduous shrubs, native to eastern and southern Asia, and particularly well represented in China, Mongolia and Japan. Bluebeards, as they are commonly named, mostly grow on sunny mountain slopes in well-drained soil. Fragrant foliage and violet-blue flowers formed in the late summer and autumn are the characteristics of Caryopteris (Miller 2007). Bluebeards are included in traditional medicine systems as remedies for arthritic pains, cough, sore throat, bronchitis and eczema (Park et al. 2014).

Phytochemical studies of Caryopteris revealed the presence of iridoids, phenylpropanoids, phenolic acids, flavonoids and the biologically active essential oil (Park et al. 2014). Besides antimicrobial (Nedorostova et al. 2009) and insecticidal (Chu et al. 2011) properties, volatile 
constituents of the investigated plants were shown to exhibit cytotoxic effects (Gao and Han 1997; Kim 2008), and can therefore be considered potential therapeutic agents.

In vitro cultures of higher plants can be regarded as an alternative, renewable source of high-value secondary metabolites (Murthy et al. 2014), with ginsenosides (Kochan et al. 2014; Liu et al. 2014), hypericin (Wu et al. 2014) and the anticancer lignan podophyllotoxin (Rajesh et al. 2014) being some of the well-known examples. As compared to field cultivation, in vitro techniques offer the possibility of continuous production of large amounts of chemically uniform biomass independently of wild resources and environmental factors (Murthy et al. 2014). As far as essential oils are concerned, in vitro cultivation also gives the possibility to obtain novel compounds, previously not reported in intact plants (Gounaris 2010; Gonçalves and Romano 2013; Marchev et al. 2014). Since the accumulation of volatile constituents was shown to be positively correlated with cell differentiation, most experiments aimed at establishing plant in vitro systems for essential oil production were conducted with the use of organ cultures. In this regard, adventitious and hairy roots are especially useful due to their fast growth and high yield of secondary metabolites (Gounaris 2010; Baque et al. 2012). Nevertheless, essential oils are often found in substantial amounts also in shoot cultures, such as those of Arnica montana (Petrova et al. 2012), Thymus caespititius (Mendes et al. 2013) and Mentha sp. (Hilton et al. 1995).

The aim of the study was to establish, for the first time, Caryopteris plant tissue cultures and evaluate their essential oil content, as well as chemical composition of the in vitro-derived volatile fractions. Although bluebeards are sometimes cultivated for ornamental value, their natural habitat, restricted due to climatic conditions, limits their utilization for medicinal purposes. Furthermore, the extraction of the volatile oil from soil-grown roots involves the destruction of the whole plant. For these reasons, the biotechnological research into plant cell cultures of Caryopteris was carried out. Three species were selected for the study: Caryopteris incana (Thunb.) Miq., Caryopteris mongolica Bunge and Caryopteris $\times$ clandonensis Simmonds, a hybrid between the two previous plants which so far has not been studied with respect to essential oil production. Given that organogenesis is known to positively affect the accumulation of volatile compounds (Gounaris 2010; Gonçalves and Romano 2013), the current research focused especially on establishing organ cultures. Gas chromatography coupled with mass spectrometry (GCMS) was used to investigate the composition of hydrodistilled essential oil obtained from aerial and underground parts of Caryopteris intact plants, as well as shoots and roots maintained under in vitro conditions. The results were discussed and compared with the available literature data.

\section{Materials and methods}

Reagents and general procedures. All reagents used for plant cell culture experiments were from Sigma-Aldrich (St. Louis, MO, USA). Water for media preparation and essential oil hydrodistillation was prepared using REL5 double water still (Mera-Polna, Przemysl, Poland). Unless otherwise stated, the in vitro cultures were maintained at $26 \pm 1{ }^{\circ} \mathrm{C}$ under white fluorescent light $(16 / 24$ photoperiod, $40 \mu \mathrm{mol} \mathrm{m} \mathrm{m}^{-2} \mathrm{~s}^{-1}$, TLD $35 \mathrm{~W}$ tubes, Philips, Amsterdam, the Netherlands). The rate of growth of the respective in vitro biomasses was expressed as the Growth index (Gi), calculated using the following formula: $\mathrm{Gi}=\left[\left(G_{1}-G_{0}\right) / G_{0}\right] \times 100 \%$ where $G_{1}$ is the fresh weight at the end of the growth cycle and $G_{0}$ is the fresh weight of the inoculum.

Seeds and in vivo plant material

Seeds of Caryopteris incana (Thunb.) Miq., Caryopteris $\times$ clandonensis Simmonds and Caryopteris mongolica Bunge were obtained from Sandeman seeds (London, UK) and used to grow the plants in vivo and to develop in vitro shoot and adventitious root cultures. The seeds for in vivo material were planted in the Medicinal Plants Garden of Medical University of Gdansk, Poland. The field-grown plants, interchangeably referred to as 'intact plants' or 'in vivo plants', were collected in October 2010 and separated to roots (referred to as 'in vivo roots') and aerial parts (also referred to as 'herbs'). The intact plant materials were dried at $30{ }^{\circ} \mathrm{C}$ and subjected to essential oil analysis.

For in vitro culture initiation, the seeds of all species were sterilized with $0.1 \% \mathrm{HgCl}_{2}$ for $30 \mathrm{~min}$, rinsed 3 times with sterile, double distilled water and placed in Petri dishes on absorbent paper soaked in a gibberellin $\mathrm{A}_{3}$ $(28.9 \mu \mathrm{M})$ and kinetin $(46.0 \mu \mathrm{M})$ solution. The dishes were kept in the dark at $26 \pm 1{ }^{\circ} \mathrm{C}$. After 2 weeks, the seedlings were obtained and subsequently used for in vitro shoot and root culture initiation.

\section{Shoot in vitro cultures}

For the induction of shoot cultures, the obtained Caryopteris seedlings were first placed on stationary $(0.7 \%$ w/v agar), phytohormone-free SH (Schenk and Hildebrandt 1972) medium supplemented with $3 \% \mathrm{w} / \mathrm{v}$ sucrose and matured for 30 days. During that time, the seedlings formed 3-4 axillary shoots which were subsequently excised and placed on SH media supplemented with different sets of growth regulators (five explants per culture jar, three containers per modification). After 30 days, the cultures were evaluated for shoot induction (Table 1) and the medium modification providing the highest multiplication rates was 
selected for further experiments. All the shoot cultures were maintained in baby food jars (Sigma-Aldrich) containing $25 \mathrm{ml}$ medium and subcultured at 30-day intervals. For the analysis of volatiles, the plant material was repeatedly collected, on 30 days of the each growth cycle, dried at $30{ }^{\circ} \mathrm{C}$ and subjected to hydrodistillation.

\section{Root in vitro cultures}

For the induction of root cultures, the sterile Caryopteris seedlings were first placed on the stationary $(0.7 \% \mathrm{w} / \mathrm{v}$ agar), phytohormone-free $\mathrm{SH}$ medium supplemented with $3 \% \mathrm{w} / \mathrm{v}$ sucrose and grown for 30 days. The roots were subsequently excised and cut into $1 \mathrm{~cm}$ fragments which were placed on SH media supplemented with different auxins. After 30 days, the explants were evaluated for root induction (Table 2) and the medium providing the highest number of roots per explant was selected for further experiments. For liquid culture initiation, the roots were

Table 1 The influence of plant growth regulators on shoot induction in Caryopteris in vitro cultures

\begin{tabular}{|c|c|c|c|}
\hline \multirow{2}{*}{$\begin{array}{l}\text { Growth regulators } \\
(\mu \mathrm{M})\end{array}$} & \multicolumn{3}{|c|}{ Number of shoots per explant ${ }^{a}$} \\
\hline & $\begin{array}{l}\text { Caryopteris } \\
\text { incana }\end{array}$ & $\begin{array}{l}\text { Caryopteris } \times \\
\text { clandonensis }\end{array}$ & $\begin{array}{l}\text { Caryopteris } \\
\text { mongolica }\end{array}$ \\
\hline TDZ (1.00) & $1 \pm 0$ & $2 \pm 0$ & $1 \pm 0$ \\
\hline 2iP (9.84) & $6 \pm 1$ & $5 \pm 1$ & $4 \pm 1$ \\
\hline BAP (8.88) & $7 \pm 1$ & $7 \pm 1$ & $6 \pm 1$ \\
\hline $\begin{array}{l}\mathrm{TDZ}(1.00)+2 \mathrm{iP} \\
(9.84)\end{array}$ & $15 \pm 2$ & $16 \pm 2$ & $14 \pm 1$ \\
\hline $\begin{array}{l}\mathrm{TDZ}(1.00)+\mathrm{BAP} \\
(8.88)\end{array}$ & $25 \pm 3$ & $30 \pm 3$ & $27 \pm 3$ \\
\hline
\end{tabular}

All cultures were maintained on solidified $(0.7 \% \mathrm{w} / \mathrm{v}$ agar) SH media supplemented with $3.0 \% \mathrm{w} / \mathrm{v}$ sucrose

$B A P$ 6-benzylaminopurine, $\quad 2 i P \quad$ 2-isopentenyladenine, $\quad T D Z$ thidiazuron

${ }^{\text {a }}$ Values represent the mean \pm SD of 15 samples

Table 2 The influence of plant growth regulators on root induction in Caryopteris in vitro cultures

\begin{tabular}{lccc}
\hline $\begin{array}{l}\text { Growth regulators } \\
(\mu \mathrm{M})\end{array}$ & \multicolumn{3}{l}{ Number of roots per explant ${ }^{\mathrm{a}}$} \\
\cline { 2 - 4 } & $\begin{array}{l}\text { Caryopteris } \\
\text { incana }\end{array}$ & $\begin{array}{l}\text { Caryopteris } \times \\
\text { clandonensis }\end{array}$ & $\begin{array}{l}\text { Caryopteris } \\
\text { mongolica }\end{array}$ \\
\hline NAA (5.37) & $1 \pm 0$ & $2 \pm 0$ & $1 \pm 0$ \\
IAA (5.71) & $1 \pm 0$ & $0 \pm 0$ & $0 \pm 0$ \\
IBA (4.92) & $15 \pm 2$ & $10 \pm 1$ & $21 \pm 3$ \\
\hline
\end{tabular}

All cultures were maintained on solidified $(0.7 \%$ w/v agar) $\mathrm{SH}$ media supplemented with $3.0 \% \mathrm{w} / \mathrm{v}$ sucrose

$I A A$ 3-indoleacetic acid, IBA indole-3-butyric acid, NAA 1-naphthaleneacetic acid

${ }^{\text {a }}$ Values represent the mean \pm SD of 15 samples transferred to $250 \mathrm{ml}$ Erlenmeyer flasks containing $100 \mathrm{ml}$ of the selected medium, supplemented with $3 \% \mathrm{w} / \mathrm{v}$ sucrose, and placed on orbital shaker (INNOVA 2300, Eppendorf, Enfield, US-CT, $25.4 \mathrm{~mm}$ stroke, $150 \mathrm{rpm}$ ). The obtained liquid root cultures were subcultured in 4-week intervals. For the analysis of essential oil, the plant material was repeatedly collected, on 30 days of the each growth cycle, dried at $30^{\circ} \mathrm{C}$ and subjected to hydrodistillation.

Isolation of volatile fraction. For the isolation of volatiles, the dried $\left(30^{\circ} \mathrm{C}, 48 \mathrm{~h}\right)$, coarsely ground plant materials of the investigated Caryopteris spp. were subjected to $3 \mathrm{~h}$ hydrodistillation (20.0 $\mathrm{g}$ of material $+200 \mathrm{~g}$ of water) using the Deryng-type distillation apparatus (Baj et al. 2013) in accordance with the method quoted in Polish Pharmacopeia VI (2002). For all biomass types, the experiment was repeated in triplicate. After evaluating the essential oil yield (expressed as percentage $\mathrm{V} / \mathrm{DW} \pm \mathrm{SD}$ ), the volatile fraction was collected, dried over anhydrous sodium sulfate and subjected to GC-MS analysis.

\section{GC-MS analysis}

Chromatographic analysis was carried out on HP-1 $30 \mathrm{~m} \times 0.25 \mathrm{~mm} \times 0.25 \mu \mathrm{m} \mathrm{m}$ capillary column, using gas chromatograph HP 5971A (Hewlett-Packard, Palo Alto, CA, USA). The analysis parameters were as follows: ionization energy $70 \mathrm{eV}$, carrier gas: helium, flow $0.5 \mathrm{ml} \mathrm{min}{ }^{-1}$, temperature increase from 80 to $300{ }^{\circ} \mathrm{C}$, at a rate of $8{ }^{\circ} \mathrm{C} \mathrm{min}^{-1}$. The resulting spectra were compared with the data from the Mass Finder 2.1. library (König et al. 2001). All experiments were repeated three times.

\section{Results and discussion}

In view of the available literature data, the essential oil of Caryopteris is characterized by a great composition variability ( $\mathrm{Pu}$ et al. 1984; Wen et al. 1990; Shatar and Adams 1999; Yang et al. 2005; Kim 2008; Upadhyaya et al. 2009; Yan and Wang 2009; Chu et al. 2011). To obtain a renewable source of standardized oil, in vitro shoot and adventitious root cultures of Caryopteris plants were initiated and established for the first time [except $C$. incana tissue cultures described by Zhang et al. (2008)].

In vitro shoot cultures of the respective species were obtained from sterile seedling fragments with the use of cytokinin-supplemented media. The plant growth regulators applied included two purine cytokinins (6-benzylaminopurine, BAP and isopentenyladenine, 2iP) and one synthetic phenylurea derivative (thidiazuron, TDZ). Due to possible synergistic effects between these two types of cytokinins in terms of shoot induction rate and positive 
influence on explant morphology (Nielsen et al. 1995; Łuczkiewicz and Piotrowski 2005; Kokotkiewicz et al. 2012), BAP and 2iP were also applied jointly with TDZ. As presented in Table 1, the combination of $8.88 \mu \mathrm{M}$ BAP jointly with $1.00 \mu \mathrm{M}$ TDZ provided the highest number of shoots per explant in all the examined species. These cultures were also characterized by relatively fast growth, as indicated by their Gi values ranging from over $500 \%$ for C. mongolica and C. $\times$ clandonensis to over $700 \%$ for C. incana (Fig. 1).

Adventitious root cultures of Caryopteris were obtained from root fragments of sterile bluebeard seedlings. To promote root growth, the excised roots were placed on auxinsupplemented media. Among the modifications used, only indole-3-butyric acid-supplemented medium (4.92 $\mu \mathrm{M}$ IBA) was shown to induce root formation (Table 2). Consequently, adventitious roots of the investigated species were further propagated in liquid $\mathrm{SH}$ medium of the above composition, providing biomass for phytochemical studies.

The established in vitro cultures were analyzed in terms of growth rate, essential oil content and composition, and the results were compared with the respective intact plants. As presented in Fig. 1, C. incana in vitro shoots and $C$. mongolica adventitious roots (depicted in Fig. 2a, b, respectively) showed the highest growth rates among the established shoot and root cultures, respectively. Adventitious roots of all investigated species were also characterized by higher growth index (Gi) values, as compared to the respective shoot cultures (Fig. 1).

The hydrodistillation of the dried plant materials gave essential oil yields ranging from ca. 0.4 to $0.8 \%$ (herbs), 1.1 to $1.3 \%$ (in vivo roots), 0.4 to $0.6 \%$ (in vitro shoots) and 1.4 to $1.8 \%$ (adventitious roots) (Fig. 3).
GC-MS of the examined essential oils revealed the presence of 64 compounds, listed in Table 3. All analyzed volatile fractions were characterized by high percentage of monoterpenes, followed by sesquiterpenes, which is in agreement with previous studies on Caryopteris (Upadhyaya et al. 2009). In general, the differences in terpenoid composition, observed between the particular materials, were mostly of quantitative nature. However, some of the compounds found in in vitro cultures were previously unreported, or present only in trace quantities in the intact plants.

As depicted in Fig. 4a and Table 3, limonene and cedrol were the dominating constituents in aerial parts of the intact plants. Contrary to cedrol, which was previously found only in Caryopteris tangutica (Yang et al. 2005), limonene was frequently mentioned in previous studies on Caryopteris (Pu et al. 1984; Wen et al. 1990; Shatar and Adams 1999). As compared to the respective herbs, in vitro shoots accumulated lower amounts of cedrol and limonene (Fig. 4b; Table 3), whereas in vivo and adventitious roots were either devoid of or produced only traces of the above constituents (Fig. 5; Table 3). The exception to this rule was the roots of Caryopteris $\times$ clandonensis intact plant which accumulated significant amounts of cedrol (Fig. 5a).

GC-MS analyses showed that beside limonene and cedrol, volatile fractions of Caryopteris herbs contained substantial amounts of $\alpha$-pinene, $\beta$-pinene, myrtenal, transpinocarveol, carvone and caryophyllene oxide (Table 3). These compounds were previously identified in aerial parts of several Caryopteris plants (Pu et al. 1984; Shatar and Adams 1999; Wen et al. 1990; Yan and Wang 2009). However, the essential oil composition varied significantly,
Fig. 1 Growth indices (Gi) of the investigated Caryopteris in vitro cultures. Values the mean \pm SD of three replicates. a In vitro cultures grown on solidified SH medium supplemented with $8.88 \mu \mathrm{M}$ BAP and $1.0 \mu \mathrm{M}$ TDZ. b In vitro cultures grown in liquid SH medium supplemented with $4,92 \mu \mathrm{M}$ IBA

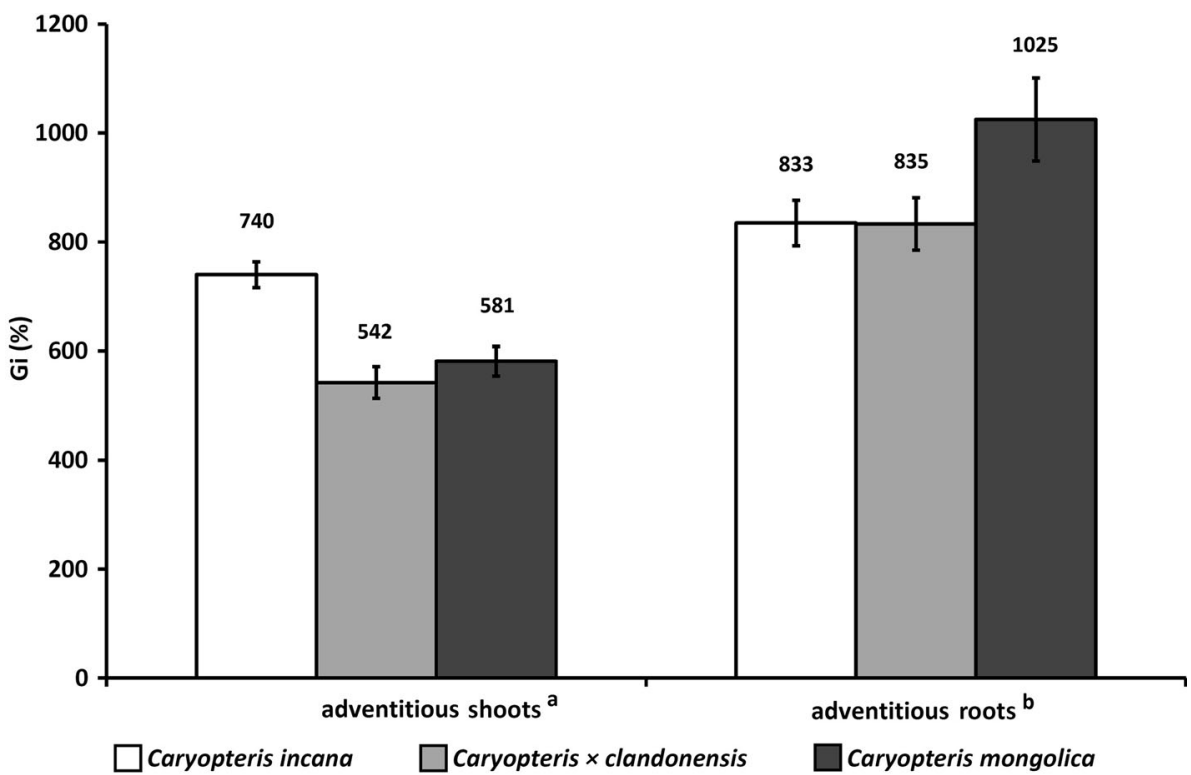



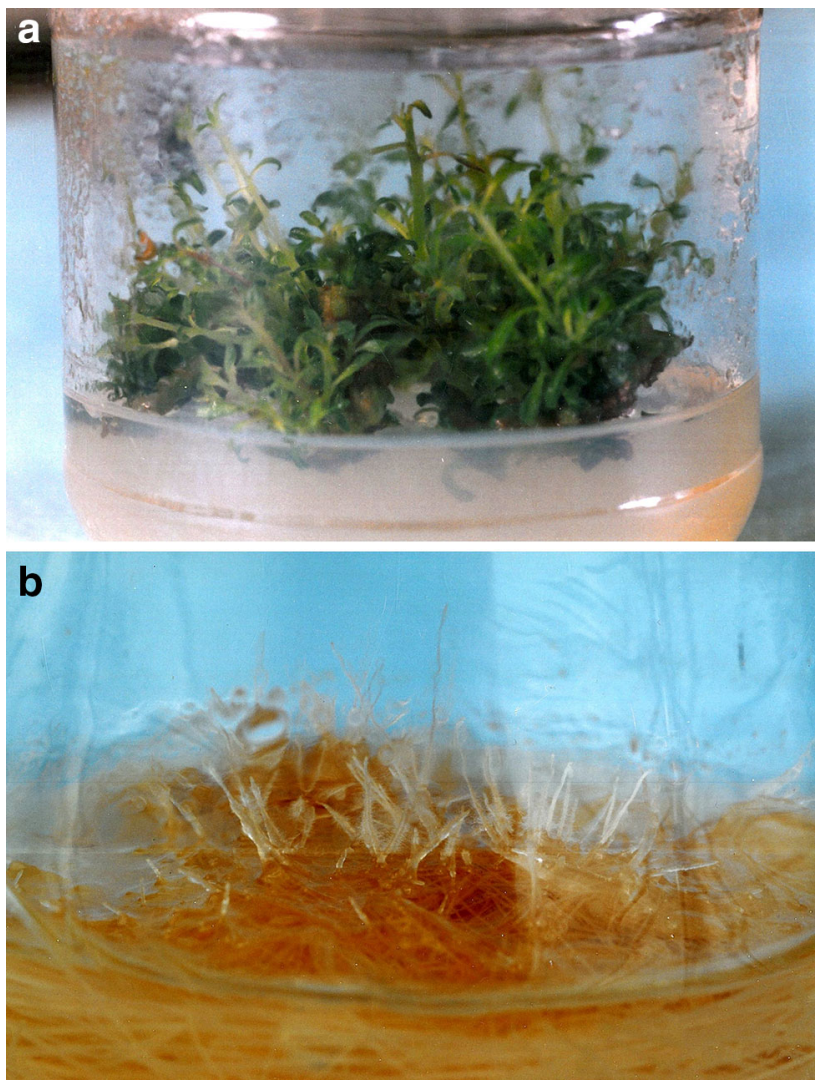

Fig. 2 In vitro cultures of Caryopteris sp.: a shoots of $C$. incana and b adventitious roots of $C$. mongolica

depending not only on the species studied, but also on the plant habitat. For instance, the presence of $\alpha$-thujene and $\beta$-ocimene in C. mongolica, reported by Shatar and Adams
(1999), was not confirmed by our research. The variability of essential oil composition was also observed in aerial parts of $C$. incana. Chu et al. (2011) reported estragole, linalool and 1,8-cineole as its major volatile constituents, whereas the study by Kim (2008) demonstrated the presence of 4,6,6-trimethyl-[1S-( $1 \alpha, 2 \beta, 5 \alpha)]$-bicyclo[3.1.1]hept-3-en-2-ol, $\tau$-cadinol, myrtenyl acetate, pinocarvone and $\delta$-3-carene in the investigated oil. According to Sun et al. (2004), C. incana oil contains linalool, perillalcohol and carvone. On the other hand, limonene prevailed in the essential oil investigated by $\mathrm{Pu}$ et al. (1984), which corresponds with our results (Fig. 4a). The essential oils examined by the above authors were collected from various locations in China and Korea. Apart from the local climatic and seasonal factors, harvesting time and storage conditions may influence the chemical composition of the Caryopteris essential oil, contributing to its great variability (Chu et al. 2011). Furthermore, it was suggested that stems, leaves and flowers of Caryopteris plants should be considered separately because of the different composition of volatiles (Yan and Wang 2009).

Given the described variation of Caryopteris volatile fraction, establishing in vitro cultures of these plants may be regarded as a step towards the standardization of the essential oil composition. As presented in Fig. 3, shoots grown in vitro had less volatile oil than herbs of the respective intact plants. However, the in vitro-derived essential oil was characterized by altered composition, manifested by the occurrence of new compounds (Table 3). For instance, 1,8-cineole, absent in intact plant materials, was the dominating (24.8-34.2\%) volatile compound of in vitro shoots (Fig. 4b). It was also surprising that the
Fig. 3 Percentage (V/DW) content of volatile oil in intact plants and in vitro cultures of various Caryopteris plants. Values the mean \pm SD of three replicates

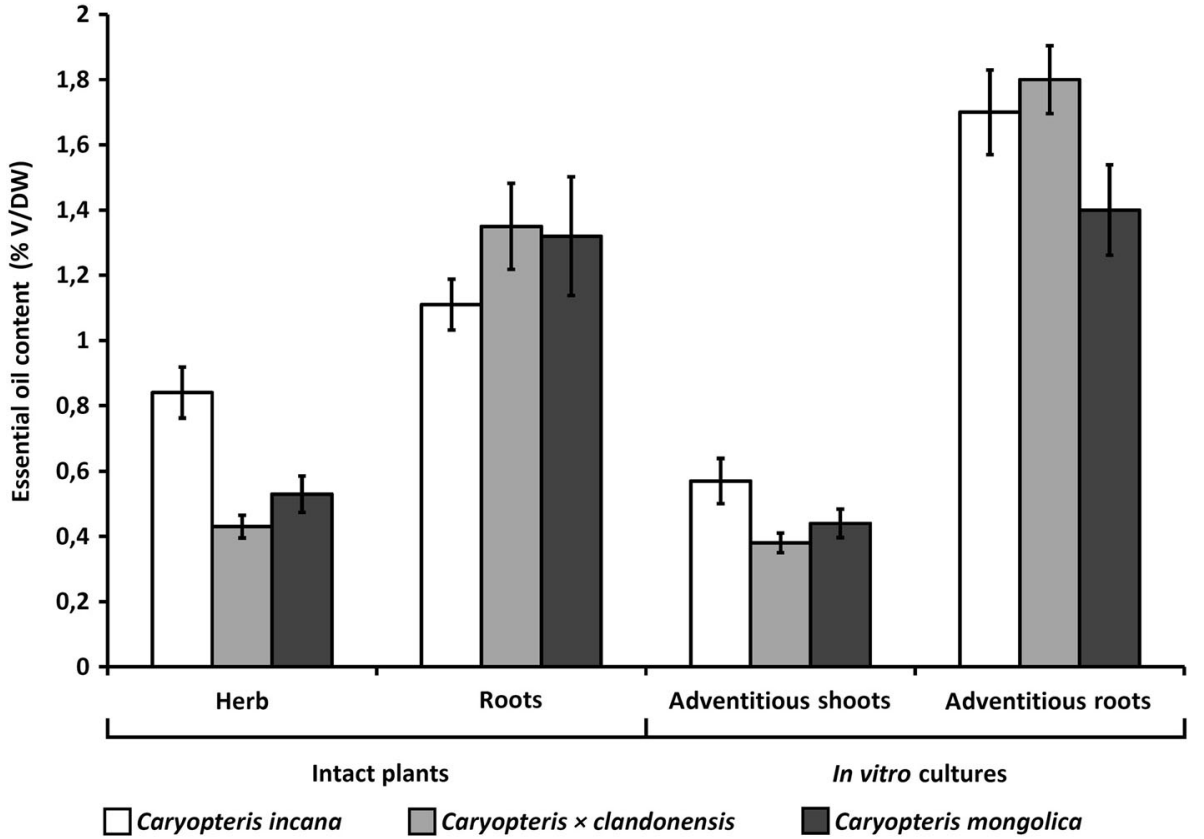


Table 3 The composition of hydrodistilled volatile oils obtained from intact plants and in vitro cultures of various Caryopteris plants

\begin{tabular}{|c|c|c|c|c|c|c|c|c|c|c|c|c|c|}
\hline \multirow[t]{4}{*}{ Compound } & \multirow[t]{4}{*}{ RI } & \multicolumn{12}{|c|}{ Relative area $(\%)^{\mathrm{a}}$} \\
\hline & & \multicolumn{4}{|c|}{ Caryopteris incana } & \multicolumn{4}{|c|}{ Caryopteris $\times$ clandonensis } & \multicolumn{4}{|c|}{ Caryopteris mongolica } \\
\hline & & \multicolumn{2}{|c|}{ In vivo } & \multicolumn{2}{|l|}{ In vitro } & \multicolumn{2}{|c|}{ In vivo } & \multicolumn{2}{|l|}{ In vitro } & \multicolumn{2}{|c|}{ In vivo } & \multicolumn{2}{|l|}{ In vitro } \\
\hline & & Herb & Roots & Shoots & Roots & Herb & Roots & Shoots & Roots & Herb & Roots & Shoots & Roots \\
\hline$\alpha$-Pinene & 925 & 3.4 & $\operatorname{tr}$ & 0.1 & - & 4.3 & - & $\operatorname{tr}$ & - & 6.0 & $\operatorname{tr}$ & 0.1 & $\operatorname{tr}$ \\
\hline Camphene & 942 & 0.3 & $\operatorname{tr}$ & $\operatorname{tr}$ & - & 0.3 & - & $\operatorname{tr}$ & - & 0.3 & - & $\operatorname{tr}$ & - \\
\hline$\beta$-Pinene & 972 & 4.3 & $\operatorname{tr}$ & 0.5 & 0.2 & 4.2 & - & $\operatorname{tr}$ & - & 3.5 & - & 2.1 & - \\
\hline 4-Octen-3-one & 973 & - & 2.6 & 0.2 & 9.8 & - & - & $\operatorname{tr}$ & - & - & 0.4 & $\operatorname{tr}$ & 3.8 \\
\hline 1-Octen-3-ol & 978 & 0.6 & - & 10.2 & 31.5 & 0.5 & 7.8 & 7.4 & 25.4 & 0.6 & 2.4 & 6.0 & 19.7 \\
\hline Myrycene +2 -pentylfuran & 985 & 0.2 & - & $\operatorname{tr}$ & - & 0.2 & 0.1 & 0.3 & 0.7 & 0.2 & $\operatorname{tr}$ & 0.2 & 0.7 \\
\hline 3-Octanol & 995 & $\operatorname{tr}$ & - & 0.3 & $\operatorname{tr}$ & $\operatorname{tr}$ & $\operatorname{tr}$ & 0.3 & $\operatorname{tr}$ & $\operatorname{tr}$ & $\operatorname{tr}$ & 0.1 & 0.1 \\
\hline 1,3,8-p-Menthatriene & 1000 & 0.1 & - & 0.1 & - & 0.3 & - & 0.2 & - & 0.1 & - & 0.2 & - \\
\hline p-Cymene & 1019 & 0.3 & - & 0.3 & $\operatorname{tr}$ & 0.4 & - & 0.3 & - & 0.6 & $\operatorname{tr}$ & 0.5 & 0.2 \\
\hline Limonene & 1025 & 16.0 & $\operatorname{tr}$ & 7.0 & - & 14.7 & $\operatorname{tr}$ & 1.6 & $\operatorname{tr}$ & 11.9 & $\operatorname{tr}$ & 1.7 & $\operatorname{tr}$ \\
\hline 1,8-Cineole & 1029 & $\operatorname{tr}$ & - & 34.2 & - & $\operatorname{tr}$ & - & 24.8 & - & - & - & 28.6 & - \\
\hline$\gamma$-Terpinene & 1054 & $\operatorname{tr}$ & - & 0.1 & - & 0.2 & - & $\operatorname{tr}$ & - & 0.2 & - & 0.3 & - \\
\hline Terpinolene & 1081 & $\operatorname{tr}$ & $\operatorname{tr}$ & $\operatorname{tr}$ & - & 0.1 & - & $\operatorname{tr}$ & - & 0.1 & $\operatorname{tr}$ & 0.1 & $\operatorname{tr}$ \\
\hline p-Cymenene & 1087 & 0.3 & - & 0.6 & - & 0.3 & $\operatorname{tr}$ & 0.7 & 0.2 & 0.2 & $\operatorname{tr}$ & 0.4 & $\operatorname{tr}$ \\
\hline Linalool & 1098 & $\operatorname{tr}$ & $\operatorname{tr}$ & 0.1 & 7.6 & $\operatorname{tr}$ & $\operatorname{tr}$ & 0.1 & 0.9 & 0.1 & $\operatorname{tr}$ & $\operatorname{tr}$ & 1.4 \\
\hline$\alpha$-Campholenal & 1124 & 0.3 & - & $\operatorname{tr}$ & - & 0.4 & - & $\operatorname{tr}$ & - & 0.5 & - & 0.2 & - \\
\hline trans- $p$-2,8-Menthadien-1-ol & 1134 & 2.3 & - & 2.9 & - & 1.2 & - & 2.5 & - & 1.5 & - & 0.6 & - \\
\hline trans-Pinocarveol & 1137 & 3.3 & - & 0.8 & - & 4.0 & - & 1.1 & - & 4.8 & - & 6.7 & - \\
\hline Camphor + trans-verbenol & 1144 & 0.3 & - & 0.1 & - & 0.5 & - & 0.6 & - & 0.8 & 0.1 & - & 0.6 \\
\hline Pinocarvone & 1159 & 2.0 & - & 0.8 & - & 2.7 & - & 0.7 & - & 3.1 & - & 6.2 & - \\
\hline (Z)-Cinnamaldehyde & 1168 & $\operatorname{tr}$ & - & - & - & $\operatorname{tr}$ & - & - & - & $\operatorname{tr}$ & - & - & - \\
\hline 4-Terpineol & 1178 & 0.4 & - & 0.1 & - & 0.6 & - & 0.1 & - & 0.7 & - & 0.6 & - \\
\hline Methylphenyl-ethanone & 1182 & 0.3 & - & 0.2 & - & 0.4 & - & 0.2 & - & 0.6 & - & - & - \\
\hline $\begin{array}{l}\text { Myrtenal + } \\
\text { myrtenol }\end{array}$ & 1193 & 4.8 & - & 2.3 & - & 4.7 & - & 1.1 & - & 4.9 & - & 10.1 & - \\
\hline 4,7-Dimethylbenzopyran & 1211 & $\operatorname{tr}$ & - & - & - & $\operatorname{tr}$ & & - & & $\operatorname{tr}$ & - & - & - \\
\hline trans-Carveol & 1217 & 3.5 & - & 1.3 & - & 2.5 & - & 0.9 & - & 2.7 & - & 0.4 & - \\
\hline Verbenon & 1224 & 0.1 & - & 1.3 & - & 0.1 & - & 0.8 & - & 0.1 & - & $\operatorname{tr}$ & - \\
\hline Carvone & 1242 & 3.7 & - & 1.0 & - & 3.8 & - & 0.6 & - & 3.5 & - & 0.2 & - \\
\hline Perillaldehyde & 1274 & 0.3 & - & 0.2 & $\operatorname{tr}$ & 0.4 & - & $\operatorname{tr}$ & - & 0.4 & - & $\operatorname{tr}$ & 0.5 \\
\hline Bornyl acetate & 1282 & 0.1 & - & $\operatorname{tr}$ & - & 0.2 & $\operatorname{tr}$ & 0.1 & $\operatorname{tr}$ & 0.1 & - & 0.1 & - \\
\hline Mentha-1,3-dien-7-al & 1285 & - & - & - & - & - & - & - & - & - & - & - & - \\
\hline$\alpha$-Copaene & 1373 & 0.4 & 2.3 & 0.4 & $\operatorname{tr}$ & 0.3 & 5.4 & 0.7 & 0.5 & 0.2 & 0.5 & 0.7 & 0.4 \\
\hline$\beta$-Bourbonene & 1389 & 0.2 & $\operatorname{tr}$ & $\operatorname{tr}$ & 0.3 & 0.1 & - & - & - & 0.2 & - & - & - \\
\hline$\alpha$-Cedrene & 1413 & $\operatorname{tr}$ & $\operatorname{tr}$ & $\operatorname{tr}$ & - & 0.2 & 0.5 & 0.1 & 0.4 & 0.2 & 0.1 & 0.2 & 0.2 \\
\hline$\beta$-Caryophyllene & 1417 & 2.3 & $\operatorname{tr}$ & 0.6 & $\operatorname{tr}$ & 2.2 & $\operatorname{tr}$ & 1.2 & $\operatorname{tr}$ & 1.5 & - & 1.4 & - \\
\hline$\beta$-Cedrene & 1422 & 0.2 & - & 0.1 & - & 1.2 & - & 0.9 & - & 0.9 & - & 0.7 & - \\
\hline$\alpha$-Humulene & 1453 & 0.7 & - & $\operatorname{tr}$ & - & 0.6 & - & 0.3 & - & 0.4 & - & 0.3 & - \\
\hline Germacrene D & 1478 & 0.5 & - & 1.2 & - & 0.5 & - & $\operatorname{tr}$ & - & 0.2 & - & 0.5 & - \\
\hline 4-Epi-cubebol & 1493 & 0.1 & - & 0.3 & - & 0.1 & $\operatorname{tr}$ & 0.2 & $\operatorname{tr}$ & 0.1 & - & 0.1 & - \\
\hline $\begin{array}{l}\text { 1-(2,3,6-Trimethylphenyl)-3-buten- } \\
\text { 2-one }\end{array}$ & 1501 & $\operatorname{tr}$ & - & - & - & $\operatorname{tr}$ & - & - & - & $\operatorname{tr}$ & - & - & - \\
\hline 3,5-Bis(1,1-dimethyl)-phenol & 1504 & $\operatorname{tr}$ & 26.2 & 0.1 & 6.0 & $\operatorname{tr}$ & 15.7 & 0.2 & 3.5 & $\operatorname{tr}$ & 12.9 & 0.5 & 4.1 \\
\hline$\beta$-Bisabolene & 1506 & 0.2 & - & 0.2 & - & 0.1 & - & - & - & 0.2 & - & - & - \\
\hline Cubebol & 1513 & $\operatorname{tr}$ & - & $\operatorname{tr}$ & - & $\operatorname{tr}$ & - & 0.2 & - & $\operatorname{tr}$ & $\operatorname{tr}$ & $\operatorname{tr}$ & $\operatorname{tr}$ \\
\hline
\end{tabular}


Table 3 continued

\begin{tabular}{|c|c|c|c|c|c|c|c|c|c|c|c|c|c|}
\hline \multirow[t]{4}{*}{ Compound } & \multirow[t]{4}{*}{ RI } & \multicolumn{12}{|c|}{ Relative area $(\%)^{\mathrm{a}}$} \\
\hline & & \multicolumn{4}{|c|}{ Caryopteris incana } & \multicolumn{4}{|c|}{ Caryopteris $\times$ clandonensis } & \multicolumn{4}{|c|}{ Caryopteris mongolica } \\
\hline & & \multicolumn{2}{|c|}{ In vivo } & \multicolumn{2}{|l|}{ In vitro } & \multicolumn{2}{|c|}{ In vivo } & \multicolumn{2}{|l|}{ In vitro } & \multicolumn{2}{|c|}{ In vivo } & \multicolumn{2}{|l|}{ In vitro } \\
\hline & & Herb & Roots & Shoots & Roots & Herb & Roots & Shoots & Roots & Herb & Roots & Shoots & Roots \\
\hline$\sigma$-Cadinene & 1516 & 0.4 & - & 0.3 & - & 0.4 & 1.5 & 1.1 & 0.1 & 0.2 & $\operatorname{tr}$ & 0.6 & 0.2 \\
\hline$\alpha$-Calacorene & 1539 & 0.1 & - & $\operatorname{tr}$ & - & 0.1 & 1.3 & 0.3 & 0.1 & 0.1 & $\operatorname{tr}$ & 0.2 & 0.2 \\
\hline Caryophyllene- $\beta$-oxide & 1549 & 0.2 & - & - & - & 0.2 & - & $\operatorname{tr}$ & - & 0.2 & - & $\operatorname{tr}$ & - \\
\hline$\gamma$-Calacorene & 1560 & $\operatorname{tr}$ & - & $\operatorname{tr}$ & - & $\operatorname{tr}$ & $\operatorname{tr}$ & 0.2 & $\operatorname{tr}$ & $\operatorname{tr}$ & - & 0.1 & - \\
\hline Caryolan-1-ol & 1574 & - & - & - & - & - & - & - & - & - & - & - & - \\
\hline Caryophyllene oxide & 1580 & 4.8 & - & 0.5 & - & 4.8 & 0.7 & 1.2 & 0.2 & 5.4 & - & 1.5 & - \\
\hline Lemnalol & 1586 & 0.4 & - & - & - & 0.4 & - & 1.6 & - & 0.3 & - & 0.6 & - \\
\hline Cedrol & 1607 & 10.9 & - & 1.4 & - & 10.9 & 8.4 & 6.1 & 0.9 & 10.7 & - & 6.4 & - \\
\hline$\tau$-Muurolol & 1642 & $\operatorname{tr}$ & - & 0.2 & - & $\operatorname{tr}$ & $\operatorname{tr}$ & 0.2 & 0.5 & $\operatorname{tr}$ & 0.2 & 0.4 & 0.8 \\
\hline $\begin{array}{l}\text { 6,10,14-Trimethyl-2-pentadecanone; } \\
\text { =hexahydrofarnesyl acetone }\end{array}$ & 1840 & - & - & 0.6 & - & $\operatorname{tr}$ & $\operatorname{tr}$ & 1.0 & 0.7 & 0.1 & - & 0.6 & - \\
\hline Isophytol & 1944 & - & - & 0.1 & - & - & - & 0.1 & $\operatorname{tr}$ & - & - & $\operatorname{tr}$ & - \\
\hline Hexadecanoic acid & 1961 & - & - & 0.8 & - & - & 2.1 & 1.3 & 3.8 & - & 2.4 & 8.0 & 7.1 \\
\hline Geranyllinalool & 2020 & - & - & 0.1 & - & - & - & 0.2 & - & - & - & 0.2 & - \\
\hline Abietatriene & 2052 & $\operatorname{tr}$ & 13.5 & 16.0 & 5.0 & $\operatorname{tr}$ & 12.7 & 10.9 & 21.6 & $\operatorname{tr}$ & 4.5 & 5.0 & 7.3 \\
\hline Heneicosane & 2100 & $\operatorname{tr}$ & 14.1 & 0.5 & 5.3 & $\operatorname{tr}$ & 8.4 & 0.3 & 2.5 & $\operatorname{tr}$ & 10.5 & - & 3.6 \\
\hline Phytol & 2105 & - & - & 4.2 & - & $\operatorname{tr}$ & - & 8.6 & 1.2 & $\operatorname{tr}$ & - & 4.8 & - \\
\hline Docosane & 2200 & - & 0.1 & $\operatorname{tr}$ & 0.9 & $\operatorname{tr}$ & 0.2 & $\operatorname{tr}$ & 0.7 & - & 0.9 & - & 1.5 \\
\hline Tricosane & 2300 & - & 12.4 & 0.2 & 14.0 & $\operatorname{tr}$ & 5.1 & 0.1 & 6.6 & $\operatorname{tr}$ & 7.5 & 0.3 & 15.0 \\
\hline trans-Totarol & 2318 & - & 2.5 & 7.0 & 3.9 & $\operatorname{tr}$ & 5.7 & 4.5 & 29.2 & $\operatorname{tr}$ & 6.9 & 4.3 & 13.5 \\
\hline Tetracosane & 2400 & - & $\operatorname{tr}$ & $\operatorname{tr}$ & $\operatorname{tr}$ & - & $\operatorname{tr}$ & $\operatorname{tr}$ & 0.3 & - & $\operatorname{tr}$ & $\operatorname{tr}$ & 0.6 \\
\hline Pentacosane & 2500 & - & 3.1 & 0.1 & 6.7 & $\operatorname{tr}$ & 3.1 & 0.1 & 6.7 & $\operatorname{tr}$ & 2.2 & 0.2 & 7.3 \\
\hline
\end{tabular}

${ }^{a}$ GC-MS data, major constituents presented in bold text

- Compound not detected, $\operatorname{tr}$ traces

essential oil obtained from in vitro shoot cultures contained abietatriene, trans-totarol and 1-octene-3-ol (Table 3), which were absent (or present in trace amounts) in the herbs, but characteristic for in vivo roots of the investigated plants.

As compared to the aerial parts, in vivo roots of the respective Caryopteris plants were characterized with higher essential oil content (Fig. 3) which also had a much simpler composition (on average, 19 compounds were identified-Table 3). There were also significant, qualitative differences in the composition of volatile fraction present in the roots, as compared to the herbs (Figs. 4a, 5a; Table 3). In all analyzed species, the dominating constituent of the root oil was 3,5-bis(1,1-dimethyl)-phenol (12.9-26.2\%). Other major compounds included abietatriene (4.5-13.5\%), heneicosane (8.4-14.1\%) and tricosane (5.1-12.4\%) (Fig. 5a; Table 3), which accumulated only in trace amounts in aerial parts of the examined species. To the best of our knowledge, this is the first report concerning the composition of root-derived Caryopteris volatile oil.

Adventitious roots synthesized large quantities of volatile oils with a composition similar to those accumulated in roots of the intact plants. However, linalool appeared as a new constituent (0.9-7.6\%), whereas the production of 3,5-bis(1,1-dimethyl)phenol, the main component of the essential oil from in vivo roots, was slowed down (3.5-6.0\%) (Fig. 5b; Table 3). Regardless of the species, the most abundant element of the adventitious root-derived oil was 1-octen-3-ol (19.7-31.5\%), present only in small quantities in the roots of soil-grown plants except for in vivo roots of Caryopteris $\times$ clandonensis, whose oil contained nearly $8 \%$ of the above compound. In addition, adventitious roots accumulated significant amounts of abietane diterpenoids; especially, adventitious root cultures of Caryopteris $\times$ clandonensis were shown to be a rich source of abietatriene and trans-totarol (21.6 and $29.2 \%$, respectively) (Fig. 5b). 
Fig. 4 Percentage content of major constituents of hydrodistilled essential oils obtained from herbs (a) and in vitro shoots (b) of various Caryopteris plants. Values the mean $\pm \mathrm{SD}$ of three replicates
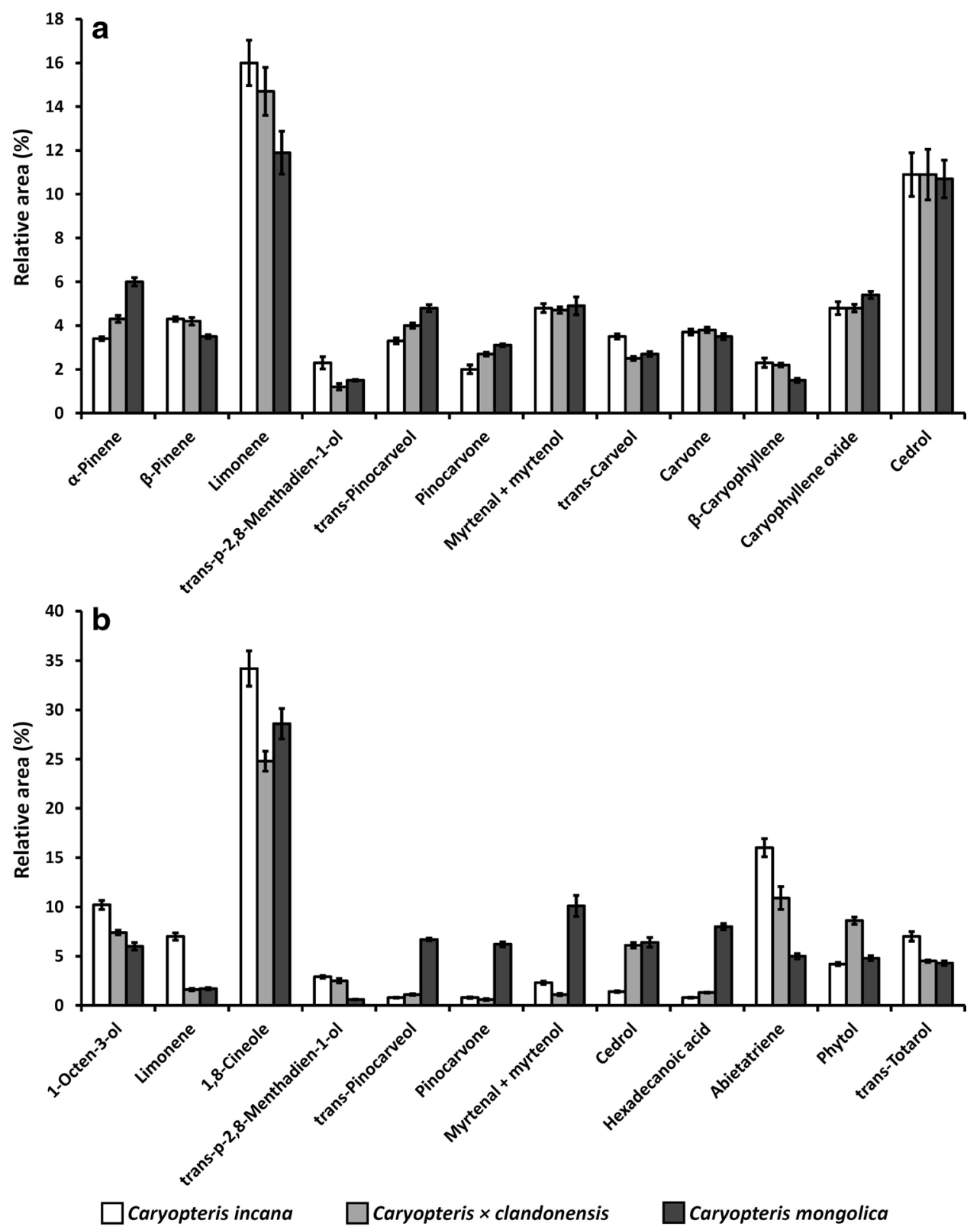

The conducted experiments demonstrated that in vitro cultures of Caryopteris accumulated high levels of medicinally relevant compounds absent in the intact plants, such as 1,8-cineole, abietatriene and totarol. The first of these constituents, abundant in in vitro shoots of the investigated plants, is a potent anti-bacterial agent (Bosnić et al. 2006) and acetylcholinesterase inhibitor (Aazza et al. 2011). The major volatile constituent of adventitious roots (1-octen-3ol) found practical application as an ingredient of mosquitorepellent devices (Burfield and Reekie 2005) and as a flavoring agent in food industry (Maggi et al. 2009). However, perhaps the most valuable constituents of Caryopteris de novo roots are abietane-type diterpenoids, previously shown to exhibit significant cytotoxic activity against human leukemia $\mathrm{HL}_{60}$ cells (Gao and Han 1997). Moreover, abietatriene was reported to display a strong gastroprotective effect, comparable to lansoprazole (Areche 2007), whereas totarol demonstrated antifungal, antimalarial and antifibrotic activities (Lee et al. 2008; Tacon et al. 2012). The latter is also a well-known antimicrobial agent against Gram-positive bacteria, used in cosmetics such as toothpastes, mouthwashes and acne preparations (Varvaresou et al. 2009). Given the high essential oil yield of Caryopteris adventitious roots, as well as the suitability of this type of biomass for industrial production of plant secondary metabolites (Murthy et al. 2008; Baque et al. 2012), the established root cultures can be considered a promising, alternative source of Caryopteris oil. Thus, further scale-up experiments in bioreactors are required to evaluate essential oil productivity of the investigated cultures. 
Fig. 5 Percentage content of major constituents of hydrodistilled essential oils obtained from in vivo (a) and adventitious roots $(\mathbf{b})$ of various Caryopteris plants. Values the mean $\pm \mathrm{SD}$ of 3 replicates
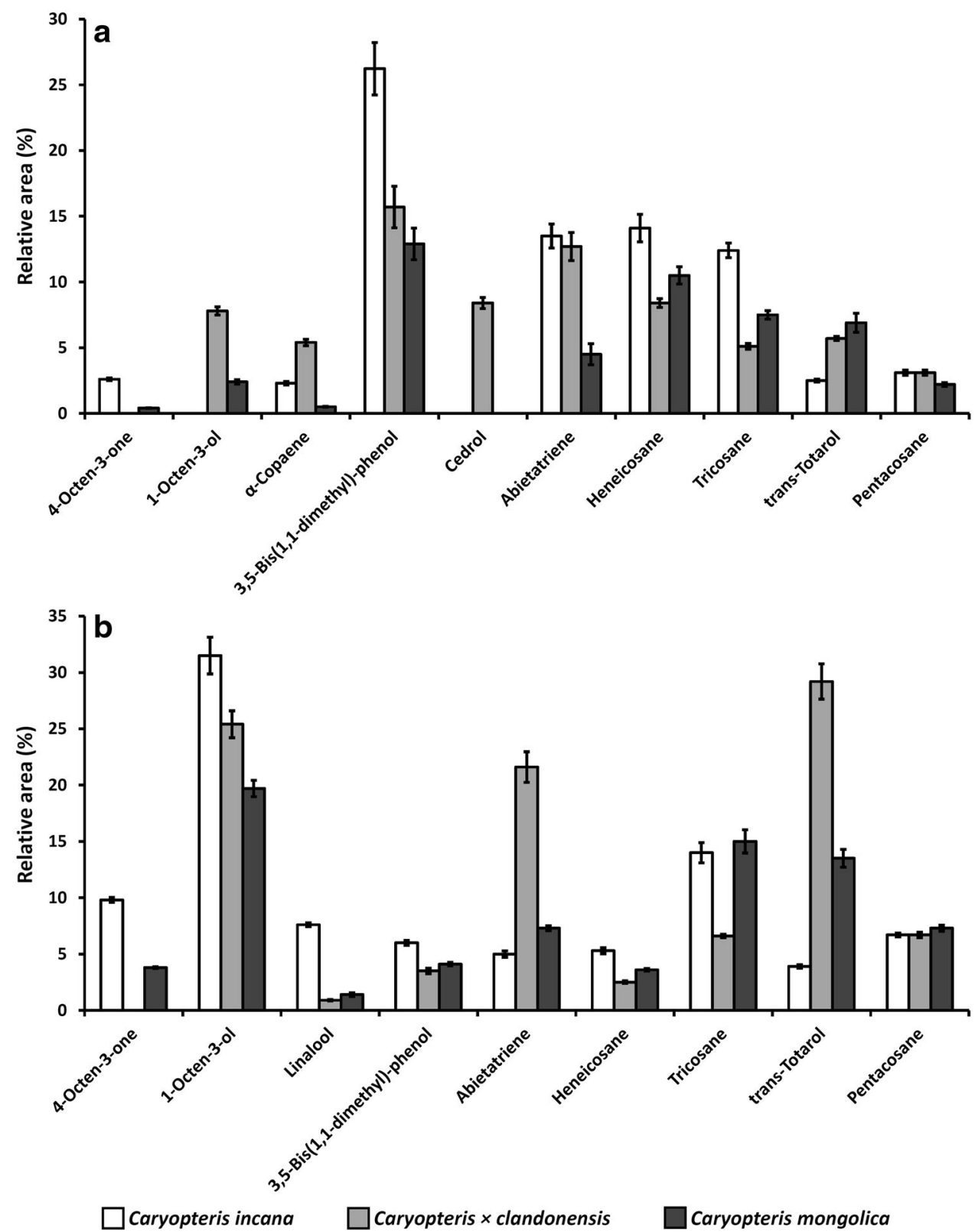

Author contribution statement M. Luczkiewicz, A. Jesionek and A. Kokotkiewicz conducted the in vitro research, analyzed the data and wrote the manuscript. P. Migas isolated the volatile fractions from the Caryopteris plant material. M. Mardarowicz, A. SzreniawaSztajnert and B. Zabiegala carried out the analysis of essential oils with GC-MS. A. Bucinski checked and corrected the manuscript. All the authors read and approved the manuscript in its final form.

Acknowledgments The authors gratefully acknowledge the financial support (DS-UPB 922) from Collegium Medicum, Nicolaus Copernicus University in Torun, Poland.
Conflict of interest The authors declare that they have no conflict of interest.

Open Access This article is distributed under the terms of the Creative Commons Attribution License which permits any use, distribution, and reproduction in any medium, provided the original author(s) and the source are credited.

\section{References}

Aazza S, Lyoussi B, Miguel MG (2011) Antioxidant and antiacetylcholinesterase activities of some commercial essential oils and their major compounds. Molecules 16:7672-7690 
Areche C, Rodríguez JA, Razmilic I, Yáñez T, Theoduloz C, Schmeda-Hirschmann G (2007) Gastroprotective and cytotoxic effect of semisynthetic ferruginol derivatives. J Pharm Pharmacol 59:289-300

Baj T, Ludwiczuk A, Sieniawska E, Skalicka-Woźniak K, Widelski J, Zieba K, Głowniak K (2013) GC-MS analysis of essential oils from Salvia officinalis L.: comparison of extraction methods of the volatile components. Acta Pol Pharm Drug Res 70:35-40

Baque MA, Moh SH, Lee EJ, Zhong JJ, Paek KY (2012) Production of biomass and useful compounds from adventitious roots of high-value added medicinal plants using bioreactor. Biotechnol Adv 30:1255-1267

Bosnić T, Softić D, Grujić-Vasić J (2006) Antimicrobial activity of some essential oils and major constituents of essential oils. Acta Med Acad 35:19-22

Burfield T, Reekie S-L (2005) Mosquitoes, malaria and essential oils. Int J Aromather 15:30-41

Cantino PD, Wagstaff SJ, Olmstead RG (1999) Caryopteris (Lamiaceae) and the conflict between phylogenetic and pragmatic considerations in botanical nomenclature. Syst Bot 23:369-386

Chu SS, Liu QZ, Zhou L, Du SS, Liu ZL (2011) Chemical composition and toxic activity of essential oil of Caryopteris incana against Sitophilus zeamais. Afr J Biotechnol 10:8476-8480

Gao J, Han G (1997) Cytotoxic abietane diterpenoids from Caryopteris incana. Phytochemistry 44:759-761

Gonçalves S, Romano A (2013) In vitro culture of lavenders (Lavandula spp.) and the production of secondary metabolites. Biotechnol Adv 31:166-174

Gounaris Y (2010) Biotechnology for the production of essential oils, flavours and volatile isolates. Flavour Fragr J 25:367-386

Hilton MG, Jay A, Rhodes MJC, Wilson PDG (1995) Growth and monoterpene production by transformed shoot cultures of Mentha citrata and Mentha piperita in flasks and fermenters. Appl Microbiol Biotechnol 43:452-459

Kim S (2008) Composition and cell cytotoxicity of essential oil from Caryopteris incana. J Korean Soc Appl Biol Chem $51: 238-244$

Kochan E, Szymańska G, Szymczyk P (2014) Effect of sugar concentration on ginsenoside biosynthesis in hairy root cultures of Panax quinquefolium cultivated in shake flasks and nutrient sprinkle bioreactor. Acta Physiol Plant 36:613-619

Kokotkiewicz A, Luczkiewicz M, Hering A, Ochocka R, Gorynski K, Bucinski A, Sowinski P (2012) Micropropagation of Cyclopia genistoides, an endemic South African plant of economic importance. Z Naturforsch 67c:65-76

König WA, Joulain D, Hochmuth DH (2001) Terpenoids and related constituents of essential oils-Library of Mass Finder 2.1. Hamburg, Germany: University of Hamburg, Institute of Organic Chemistry

Lee MK, Yang H, Yoon JS, Jeong EJ, Kim DY, Ha NR, Sung SH, Kim YC (2008) Antifibrotic activity of diterpenes from Biota orientalis leaves on hepatic stellate cells. Arch Pharm Res 31:866-871

Liu H, Wang J, Gao W, Wang Q, Zhang L, Man S (2014) Optimization and quality assessment of adventitious roots culture in Panax quinquefolium L. Acta Physiol Plant 36:713-719

Łuczkiewicz M, Piotrowski A (2005) Two-stage system for micropropagation of several Genista plants producing large amounts of phytoestrogens. Z Naturforsch 60c:557-566

Maggi F, Bílek T, Lucarini D, Papa F, Sagratini G, Vittori S (2009) Melittis melissophyllum L. subsp. melissophyllum (Lamiaceae) from central Italy: A new source of a mushroom-like flavour. Food Chem 113:216-221

Marchev A, Haas C, Schulz S, Georgiev V, Steingroewer J, Bley T, Pavlov A (2014) Sage in vitro cultures: a promising tool for the production of bioactive terpenes and phenolic substances. Biotechnol Lett 36:211-221

Mendes MD, Figueiredo AC, Oliveira MM, Trindade H (2013) Essential oil production in shoot cultures versus field-grown plants of Thymus caespititius. Plant Cell Tiss Organ Cult 113:341-351

Miller D (2007) Caryopteris. Supplementary to RHS Trials and Awards: Number 2, December 2007. In: RHS Plant Trials and Assessments. Royal Horticultural Society. http://apps.rhs.org.uk/ planttrials. Cited 31 Mar 2014

Murthy HN, Hahn EJ, Paek KY (2008) Adventitious roots and secondary metabolism. Chin J Biotechnol 24:711-716

Murthy HN, Lee E-J, Paek K-Y (2014) Production of secondary metabolites from cell and organ cultures: strategies and approaches for biomass improvement and metabolite accumulation. Plant Cell Tiss Organ Cult 118:1-16

Nedorostova L, Kloucek P, Kokoska L, Stolcova M, Pulkrabek J (2009) Antimicrobial properties of selected essential oils in vapour phase against foodborne bacteria. Food Control 20:157-160

Nielsen JM, Hansen J, Brandt K (1995) Synergism of thidiazuron and benzyladenine in axillary shoot formation depends on sequence of application in Miscanthus X ogiformis 'Giganteus'. Plant Cell Tiss Organ Cult 41:165-170

Park S, Son MJ, Yook C-S, Jin C, Lee YS, Kim HJ (2014) Chemical constituents from aerial parts of Caryopteris incana and cytoprotective effects in human HepG2 cells. Phytochemistry 101:83-90

Petrova M, Zayova E, Vassilevska-Ivanova R, Vlahova M (2012) Biotechnological approaches for cultivation and enhancement of secondary metabolites in Arnica montana L. Acta Physiol Plant 34:1597-1606

Polish Pharmacopoeia VI (2002) Polish Pharmaceutical Society. Poland, Warsaw, $\mathrm{p} 151$

Pu Z, Shi Y, Yang Y, Zhang J, Lu Y (1984) Chemical constituents of the essential oils of Chinese Caryopteris Bunge. I. GC/MS analyses of the hydrocarbon fraction of Caryopteris incana, $C$. trichosphaera, $C$. forrestii and C. forrestii var. minor. Acta Chim Sin 42:1103-1105

Rajesh M, Sivanandhan G, Muthukrishnan A, Venkatachalam V, Theboral J, Girija S, Manickavasagam M, Selvaraj N, Ganapathi A (2014) Factors influencing podophyllotoxin production in adventitious root culture of Podophyllum hexandrum Royle. Acta Physiol Plant 36:1009-1021

Schenk RU, Hildebrandt AC (1972) Medium and techniques for induction and growth of monocotyledonous and dicotyledonous plant cell cultures. Can J Bot 50:199-204

Shatar S, Adams RP (1999) The essential oil of Caryopteris mongolica Bung. from Mongolia. J Essent Oil-Bear Plants 2:25-28

Sun L, Chen H, Ye W (2004) Studies on chemical constituents of the volatile oil from Caryopteris incana (Thunb.) Miq. J Jiangxi Norm Univ 28:196-199

Tacon C, Guantai EM, Smith PJ, Chibale K (2012) Synthesis, biological evaluation and mechanistic studies of totarol aminoalcohol derivatives as potential antimalarial agents. Bioorg Med Chem 20:893-902

Upadhyaya K, Dixit VK, Padalia RC, Mathela CS (2009) Chemical composition of the essential oil of Caryopteris grata. Benth. J Essent Oil Res 21:69-70

Varvaresou A, Papageorgiou S, Tsirivas E, Protopapa E, Kintziou H, Kefala V, Demetzos C (2009) Self-preserving cosmetics. Int J Cosmet Sci 31:163-175

Wen M, Xiao S, Wu Y, Huang Y, Ren W, Zhao H (1990) Chemical components of the essential oil from Caryopteris glutinosa. Nat Prod Res Dev 2:19-22 
Wu S-Q, Yu X-K, Lian M-L, Park S-Y, Piao X-C (2014) Several factors affecting hypericin production of Hypericum perforatum during adventitious root culture in airlift bioreactors. Acta Physiol Plant 36:975-981

Yan P, Wang ZZ (2009) Analysis of essential oil from different organs of Caryopteris tangutica. Chin Med Mat 32:61-65
Yang A, Lu R, Liu J, Shi G (2005) Study on volatile components of Caryopteris tangutica Maxim. Chin J Chin Mat Med 30:233-234

Zhang Q-Y, Ma D-D, Chen R, Huang L-C, He Y-Y, Li G-Y (2008) Tissue culture and rapid propagation of Caryopteris incana (Thunb.) Miq. Plant Physiol Commun 44:535 